\begin{tabular}{|ccc|}
\hline & ANNALES INSTITUTI SLAVICI \\
& UnIVERSITATIS DEBRECENIENSIS & \\
SLAVICA XLVII & 2018 & DEBRECEN \\
\hline
\end{tabular}

Klára AGYAGÁSI

\title{
ДВОЙНЫЕ РУССКИЕ ЗАИМСТВОВАНИЯ В МАРИЙСКОМ ЛЕКСИКОНЕ
}

\section{Double Russian Lexical Copies in the Mari Lexicon}

The author aims to reconstruct the phonetic, morphological, semantic and chronological

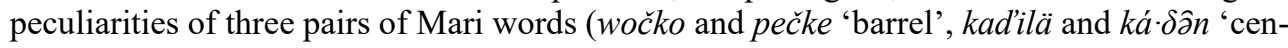
ser', mol'o and mülo 'young fish') borrowed from Russian dialects. She comes to the conclusion that they can compose pairs as direct and indirect borrowings, different derivational varieties of the same verbal stem or the phonetically resembling Mari representations of two etymologically different Russian dialectal words.

Keywords: double lexical copies, direct and indirect Russian borrowings in Mari, derivational varieties of Russian verbal stems in Mari

\section{о. Введение}

В истории исследования русских заимствований в марийском языке с самого начала был поднят вопрос о классификации русизмов в хронологическом и ареальном подходе. Селищев [СЕлищЕВ 1927], Серебренников [SEREBRENNIKOV 1957: 229], Грузов [ГрузОв 1964: 108], Берецки [BERECZKI 1968] и Саваткова [САВАТКОВА 1969: 9-14] все они указывали на ту особенность русских заимствований в марийском, что часть этих слов попала в марийский язык непосредственно из русского, но значительное количество (преимущественно самые ранние русские заимствования) заимствовалось посредством чувашского языка ${ }^{1}$. Но до сих пор не был выявлен и не был изучен в сопоставительном плане тот особый слой русских заимствований, который можно назвать условно как группа двойных заимствований.

Под двойными заимствованиями понимаются нами такие лексические элементы марийского словаря, которые

a) по своему происхождению восходят к одному и тому же русскому оригиналу, но они заимствовались два раза: непосредственно из русского, и посредством одного из диалектов волжско-булгарского или татарского языка. Такие слова образуют две словарные статьи и представляют два параллельных ряда данных в марийском словаре;

1 Исследования последних лет в области ареальной лингвистики Волжско-Камского региона показали, что опосредование лексических элементов доминантным волжско-булгарским языком в окружающие финно-угорские языки являлось одним из основных действующих механизмов этого языкового ареала (см. подробнее AGYAGÁSI 2014). 
б) наличествуют в марийских диалектологических словарях внутри одной словарной статьи в виде фонетических вариантов, но в действительности эти варианты восходят к разным (двум) русским оригиналам;

в) наличествуют в марийских диалектологических словарях внутри одной словарной статьи в виде словообразовательных вариантов. Они имеют общий корень и разные суффиксы русского происхождения, а лексическое значение словообразовательных вариантов совпадает. Ниже будет проведен историкоэтимологический анализ образцов каждого подтипа.

\section{1. Мар. во́чко 'кадка, кадуша'}

Лексеме марийского литературного языка вочко 'кадка, кадуша' в марийских диалектах соответствуют два слова (во́чко и пе́чке, см. подробности в этимологической базе данных) в том же значении. Основная разница между ними состоит в том, что слово в первом случае имеет задний вокализм, соответственно русскому бочка, с которым оно сравнивалось в прежней литературе на основании современной русской диалектологии [см. САВАТКОВА 1969: 90], а во втором случае вокализм передний. Передний вокализм показывает тоже чувашское соответствие этого слова, которое восходит к тому же самому русскому оригиналу [см. АДяГАШи 2005: 74-75]. Как на это обратил внимание Берецки [BERECZKI 1994: 138-142], в истории марийского языка не существовали такие регулярные фонетические изменения, в результате которых гласные заднего ряда имели бы внутреннюю историческую причину переходить в свои передние соответствия. Палато-велярная гармония гласных возникла в марийском только как вторичное явление западных говоров под поздним влиянием чувашского и татарского языка, и реализовалась только между корнем и суффиксами. Таким образом слово пе́чке могло образоваться не в марийском, а в ранне-среднечувашском языке как реципиентная форма при заимствовании старорусского прототипа бо́чка из полноокающих волго-камских владимиро-поволжских говоров северного диалекта русского языка (фонетические особенности этих говоров см. подробно СмОЛякОВА 1977: 31-47).

$$
\text { Ст.русс./С.диал. [bóčka] } \rightarrow \text { ранне-ср.чув. *pečke } \rightarrow \text { поздне-прамар. *pečke }
$$

В этом говоре аффрикаты $\check{c}$ и $c$ были противопоставлены друг другу, конечный гласный $a$ в безударном положении сохранил оба дифференцирующих признака, и остался в произношении как $a$. Для ранне-среднечувашского языка было характерно наличие вторичного $\check{c}$, отсутствие начального $b$ и кратких лабиальных гласных среднего подъемя, а смычный гуттуральный согласный $k$ имел переднюю артикуляцию (в противопоставлении с $x$, развившегося из более древнего $q$ задней артикуляции). При заимствовании русских слов, имевших согласный $k$ в своем составе, именно адаптация русского $k$ с передней артикуляцией привела к изменению гласной структуры слова по принципу тюркского сингармонизма (подробную характеристику ранне-среднечувашского языка см. AGYAGÁSI 2019). 
Средне-чувашская форма заимствовалась поздне-прамарийским языком, который во время начала чувашско-марийских контактов территориально уже распался на две части. Заимствование среднечувашской формы *pečke свидетельствует о том, что изменение согласного $\check{c}$ в его диалектах еще следует за регу-

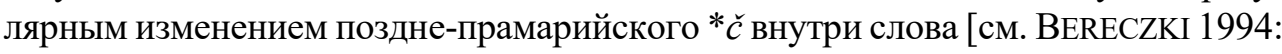
50], но структура прамарийских двухсложных слов с открытым слогом в конце (оканчивающихся регулярно на *ə̧) $)^{2}$ при заимствовании не была удержана.

То же самое русское слово, но уже задним вокализмом, также представлено в марийском языке (см. во́чко в базе данных). Оно распространилось по всей марийской языковой территории, зарегистрировано во всех говорах двух больших диалектов. Структура марийских соответствий указывает на присутствие редуцированного гласного в конце русской донорной формы. Это можно объяснить двояким образом: соответственно первому, редуцированный гласный был свойствен русскому прототипу, служившему предметом заимствования. Такая фонетическая реализация заударного гласного стала возможной после падения редуцированных поздне-праславянского периода и появления динамического ударения первоначально в южном диалекте древне-русского языка ${ }^{3}$.

Но появление редуцированного гласного на месте русского этимологического - $a$ второго открытого слога можно объяснить и изменением, мотивированным прамарийскими структурными нормами. К поздне-прамарийскому периоду любой гласный финно-угорского происхождения во втором открытом слоге сузился до потерия своих дифференцирующих признаков. Поздне-прамарийский протопип *V-a двухсложных слов (ср. примеры у Bereczki 1992, № $6,9,34,38,49,63,86,88,93,95,97,100,104,119,121,125,137,138,176$, $177,187,195,196,197,201,202,206,214,217,219,223,226,229,233,240,244$, $245,254,256,263,265,266,267,287,291,301,328,329,330,341,343,345,347$, $363,373,379,383,389,395,416,422,483)$ стал структурной нормой для адаптации ранних заимствований с оригинальной структурой $V$ - $V$. Гласный -о- первого слога донорной формы также имеет регулярное соответствие прамарийского *o первого слога слов финно-угорского и уральского происхождения [cм. BERECZKI 1994: 92-95], то есть в западном диалекте в горном наречии имеются формы на - $a$ - в первом слоге.

Предположение о том, что русское слово было заимствовано во время позднепрамарийского периода, кроме современных междиалектных соответствий гласных фонем поддерживается и междиалектными соответствиями прамарийского сочетания *-čk- в современных диалектных вариантах марийского слова. Эти соответствия полностью совпадают с теми диалектными фонетическими признаками данного сочетания $(*-c ̌ k>*-c k$ - $>$ *-ćk- $\sim-c k-\sim \dot{s} k)$,

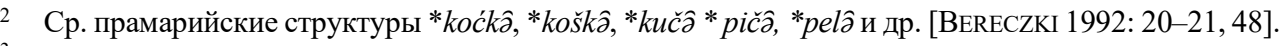
Представители южного диалекта древнерусского языка появились в Среднем Поволжье и образовали острова среди окающих говоров после татарского нашествия. После того так монголы в 1237 г. разорили ряд южнорусских городов (как Воронеж, Белгород, Рязань, Кострома), население бежало в северное направление [Скрынников 1997: 126-147]. 
которые встречаются в современных исконных марийских словах финно-угорского или уральского происхождения [см. BERECZKI 1994: 33, 50], как регулярное продолжение прауральского сочетания *-čk.

Параллельное заимствование русского слова через средне-чувашский и непосредственно из русского языка дает основание предположить, что предмет, обозначенный словом, взятым из двух источников, являлся товаром для марийского населения.

Несмотря на то, что в прежней литературе исследователи началом непосредственных русско-марийских языковых контактов считали середину XVI-го века, на основании этого примера можно допустить более раннее время заимствования. На наш взгляд изученное слово могло заимствоваться из языка древнерусских торговцев непосредственно поздне-прамарийским языком, когда территории древнерусского и прамарийского населения географически еще не соприкасались, ср. др. русск. [*bóćka] $\rightarrow$ поздне-прамар. * $\beta о c ̌ k \hat{. ~}$

\section{2. Мар. кадила г. 'кадило'}

Предмет, который обозначается словом кадило в русском языке, является средством православных церковных обрядов. Тот факт, что это слово было заимствовано из русского языка западными говорами марийского языка, говорит о том, что христианизация марийцев оставила свои следы и в марийском языке, вопреки тому, что марийцы до XX века хранили свои народные верования. По общераспространенному мнению [см. обзор у ЕФимОВА 2000: 220-222] принятие православной веры народами Поволжья, среди них некоторыми марийскими общественными группами произошло в XVIII -ом году, когда были приняты меры и созданы учреждения ${ }^{4}$ для обучения на русском языке детей «инородцев» государством и православной церковью. Русский язык XVIII -ого века в Среднем Поволжье существовал все еще на уровне диалектов. Для этого времени предполагается заимствование русских слов, связанных практикой вероисповедания или непосредственно из церковнославянского языка, произнесенного русскими священниками, или из их диалектной речи.

В марийском литературном языке, в северо-западном и западном наречии марийского языка а также в горном наречии имеются разные по форме, но одинаковые по значению слова для обозначения сосуда для курения при богослужении. Видимо, имеем дело с словообразовательными вариантами, которые попали в марийскую лексику из разных источников. Варианты kadila и kadilä восходят к русскому существительному [kad'il $]$, которое в равной мере присутствовало в русской церковной, а оттуда также в диалектной речи. Из-за реализации в марийском заударного гласного в виде $[\wedge]$ донорная форма может

4 В 1735 г. появился указ правительства об открытии новокрещенских школ, в 1740 г. было учреждено Конторой новокрещенских школ в гг. Свияжске, Елабуге, Казани и Царевококшайске, в 1775 г. были изданы в Санкт-Петербурге «Сочинения, принадлежащие к грамматике черемисского языка» Митрополитом Вениямином Пуцек-Григоровичем. 
восходить к среднему диалекту русского языка. В горном наречии конечный [^] подвергался изменению $a>\ddot{a}$ (см. Bereczki 1994: 128-129).

В то же время, в горном наречии, в окресности г. Козьмодемянска известно

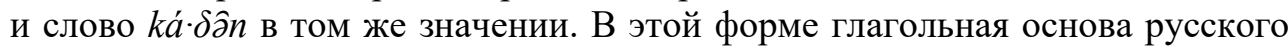
слова (кад-) легко выделяется, но немного труднее определить оригинальную морфологическую структуру донорной формы русского производного слова. В значении имени действия в церковнославянском языке известна форма каждємІє [СЦСРЯ 2: 151], в русской редакции кажємІе [там же], но в русском эквиваленте марийского слова не может быть речи о праславянском образовании типа *kad-jenbj-e [см. ВАРБОТ 1969: 94-95], ведь в слове не произошла йотовая палатализация и - в ее вследствие - чередование основы. Здесь можно опираться только на единственное данное, сохранившееся из XIV века. В памятнике «Книга числь по сп. Троицко-Сергіевой лавры XIV века» была зафиксирована форма кадємиє, которая могла возникнуть после падения редуцированных по аналогии с древнерусскими образованиями с суффиксом -enьје. При адаптации русской диалектной формы [k^d'én'jb] в западном диалекте марийского языка еще были в действии марийские структурные нормы. Соотвтественно этим нормам в трехсложных словах гласный второго, закрытого слога встречался чаще всего как редуцированный гласный, см. прамарийские формы y Bereczki 1992: *kurmâćak (№ 111); *kuwâlćâ (№ 122); *muškŝndâ (№ 200); *pušâmวิš (№ 272). Палатализованный согласный $d$ ' субституировался через $d$. В более ранних заимствованиях из русского языка русские родовые окончания в марийских формах не сохранились из-за типологических причин. Марийский, как агглютинирующий язык не имеет категории рода в своей системе, таким образом родовые окончания для носителей этого языка не являлись значимыми морфемами и часто подвергались структурным изменениям, ср. русск. внимание $\rightarrow$ луг. нареч. мар. яз. minumanij [САВАТКОВА 1969: 92], скирда $\rightarrow$ луг. $\hat{s} k \hat{r} r t$, горное нареч. askart [САВАТКОВА 1969: 115]. Таким образом имеем причину предполагать, что конечная морфема -је донорной формы в конце слова вообще не участвовала в марийской реципиентной форме при заимствовании, а мягкий согласный $n$ ', оказавшийся в конце слова, как правило, отвердел (см. САВАТКОВА 1969: 36). В итоге сопоставительного анализа параллельных форм западного диалекта марийского языка (kadilä и ká. $\delta \partial \hat{n})$ можно заключить, что они являются словообразовательными вариантами, возникшими в русских диалектах до формирования русского литературного языка. Первый из них фигурирует в русском языке как общеупотребительное слово на уровне разговорного и диалектного языка, а второй является архаическим диалектизмом ${ }^{5}$.

5 Марийские диалекты сохранили в своей лексике некоторые архаические диалектизмы русского происхождения, которые со времени заимствования исчезли даже из русских донорных источников, ср. AgYAGÁsI 2013. 


\section{3. Мар. мо́льо 'малявка (рыба)'}

Слово со значением 'мелкая рыба' в литературном языке и в горном наречии западного диалекта ${ }^{6}$ марийского языка представлено в формах мо́льо $m o ́ l l \hat{s}$, в йошкар-олинском говоре центрального диалекта ${ }^{7}$ оно имеет формы как $m ø l o ́ \sim m ø \cdot l o$, (в современной транскрипции этим вариантам соответствует

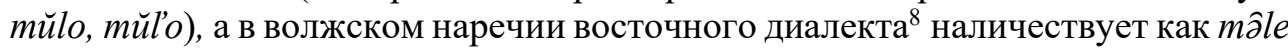
$\sim m \hat{\imath} \cdot l \dot{l}$. Эти варианты не могут быть рефлексами одной русской донорной формы, заимствованной в среднерусском периоде, потому что в истории марийского языка прамарийский гласный *o в первом слоге ни в одном из наречий не изменялся в - $u$ - или в редуцированный гласный, ср. современные диалектные соответствия прамарийского *ponds 'Stock, Stab': P B M wondo,

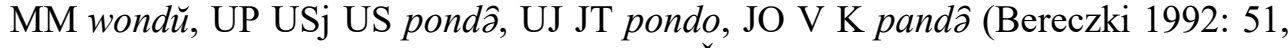

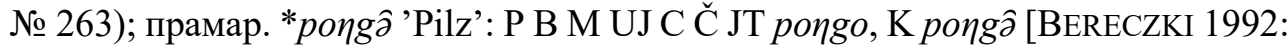
51, №265] и др. Также не известны такие причины, в результате которых прамарийский -u- изменился бы в первом слоге в -о-. В русских диалектах к трем марийским формам противопоставлются два разных слова (молье и мулье) в том же значении, являющиеся собирательными образованиями от разных славянских основ предположительно не раньше среднерусского периода ${ }^{9}$. Марийская литературная форма и форма лугового и горного наречия (лит., луг. мол'o, г. мол'bl, móll'â) - на основании приведенных марийских примеров - могут восходить к русскому слову [moljjo], существовавшему в полноокающих наречиях северного диалекта русского языка, ведь в них гласный -о- первого слога русской формы сохранился, а гласный второго слога отражает изменение, вызванное марийскими структурными особенностями, ср. примеры выше.

А формы mŭlo $\sim$ mŭlo и mâle $\sim$ mîl' l' такому объяснению не поддаются.

Варианты mŭlo mŭl'o были записаны в собирательных пунктах JT и Mup в йошкар-олинском говоре ${ }^{10}$, в котором, вместе с волжским говором, время произношения гласного $* u$ первого слога прамарийского происхождения стало сверхкратким под влиянием среднечувашского языка [см. АДяГАши 2002а: 74-75, 85]. В них сверхкраткий $\breve{u}$ может отражать русский [u] слова [muljó], заимствованного из северного диалекта русского языка (см. базу данных) до изменения $u>\breve{u}$ в йошкар-олинском говоре. Это предположение подтверждается диалектными соответствиями исконно-марийских слов с гласным *u в первом слоге, см. прамар. *purวิ- 'beißen, kauen': P B M U CÜ puram, CK С̆ JT pŭram, K pâram [BERECZKI 1992: 54, № 280]; прамар. *lukŝ 'Ecke, Biegung': CK Č JT lŭk, K làk [BERECZKI 1992: 34, № 165].

6 Данные из этого наречия у Саватковой обозначаются как г., у Беке через К (собиратеьный пункт Козьмодемянск), у Моисио-Сааринен как $\mathrm{W}_{1}$, см. этимологическую базу данных.

7 См. ЈT У БЕКЕ, МUР У МОИСИО-СААРИНЕН.

8 У Беке собирательные пункты СК С̆, у Моисио-Сааринен Мwo.

9 Собирательные существительные молье и мулье в письменных памятниках не зафиксированы, они сохранены только диалектами русского языка.

10 Этот говор Берецки причисляет к западному диалекту [см. BERECZKI 1994: 21-24], а Моисио и Сааринен считают представителем среднего диалекта [MOISIO-SAARINEN 2008: VIII-IX]. 
Марийские формы $m \hat{\partial} l e \sim m \hat{\imath} \cdot l ' \varepsilon$ известны из волжского наречия западного диалекта (собирательные пункты СK и С̆ у Беке, Мwо у Моисио и Сааринен). Они содержат редуцированный гласный в первом слоге. Этот редуцированный по правилам исторического изменения марийских гласных не может восходить ни к оригинальному $*$, ни к $* u$. Он может быть современным соответствием прамарийского * $i$, если говорится об исконном слове [см. BERECZKI 1994: 105], или отражением редуцированого гласного донорного языка. Иллабиальный редуцированный, развившийся из гласного $u$ наблюдается в центральном диалекте татарского языка, ср. старорусск. [suslo] 'сладковатый навар на муке и солоде' $\rightarrow$ среднекыпч. *susla > тат. (Ц.гай.) sĭsla 'то же ' [АДягАши 2005: 194 95], или в мишарском, как это отражается в соответствии русск. мулье в форме mělĕ в байкобаевском наречии мишарского диалекта (на котором говорят в Башкортостане). Но в случае волжского наречия марийского языка нельзя говорить о марийско-татарских непосредственных отношениях. Здесь можно учитывать только контакты с верховым диалектом чувашского языка и субстратным языком народности, названной в исторических источниках под именем «нижняя черемиса» (см. АДяГАши 2002б: 106). Так как, к сожалению, соответствующих данных из этих языков не сохранились, точно определить источник последних фонетических вариантов невозможно. Но относительно совокупности сохранившихся марийских диалектных вариантов можно прийти к выводу, что они являются заимстованиями двух русских слов, пришедших в марийские диалекты через три канала.

Этимологическая база данных

Мар. во́чко 'кадка, кадуша' (МРСл)

Марийские данные:

1 .

Мар. диал.: л. во́чко, в. во́чко, г. ва́чкы 'бочка' [САВАТкОВА 1969: 90]; Р ВЈр

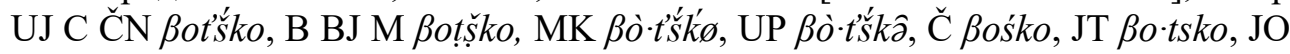

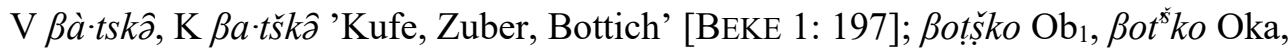

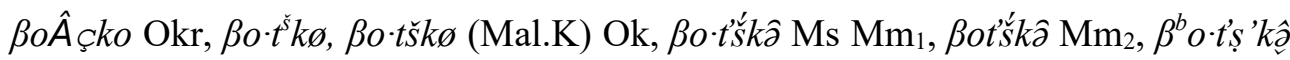

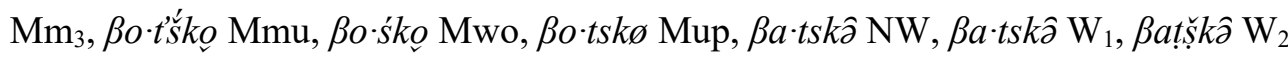
'Holzschüssel (Ob Ok Ms Mup NW W ${ }_{1}$ ) (ein kleines gefäß, es werden darin Fleisch, Gurken, Kohl in Salz eingelegt od. es wird darin Wasser aufbewahrt) ( $\mathrm{Ob}_{1} \mathrm{Ok} \mathrm{Ms}$ $\mathrm{Mm}_{1}$ Mup NW W $\mathrm{W}_{1}$ ), (ein großes Gefäß, in dem Korn aufbewahrt wird) $\left(\mathrm{Ob}_{1} \mathrm{Ok} \mathrm{Ms}\right.$ $\mathrm{Mm}_{1}$ Mup NW), (ein großes Gefäß, in dem Bier aufbewahrt wird) (Ok Ms), Kübel, Zuber, Bottich (Oka Okr Ok Ms $\mathrm{Mm}_{1} \mathrm{Mmu}$ Mwo), hölzerner Bottich (Mwo W 2 ) [MOISIO-SAARINEN 2008: 44]. 
2.

Мар. диал.: л. пе́чке, в. пе́чке, г. пе́икӓ 'бочка' [САВАТковА 1969: 90]; Р В M U C pečke;, Č peśke·, J V pe·cke, K pe·ckä 'Faß, Tonne' [BEKE 6: 1820];

Мap. ист. (1775 г.) печкѐ 'бочка' [SEBEOK-RAUN 1956: 33]; [ДАМАскИН 1785 г.] пеикѐ 'бочка' (Сергеев 2003: 59).

Чувашские данные:

Чув. лит.: pičke 'бочка, бочечный, бочковый' [СКвоРцОВ]; Чув. диал.: А pičke, pičěke, piśke 'бочка' [Ашм. 9: 236, 248-49; PAASONEN 105]; Чув. ист. (1785 г.) бичка 'бочка' [ДАмАскин].

Русские данные:

Русск. лит. 'большой деревянный или металлический цилиндрический сосуд, обычно слегка выпуклый посредине, с двумя плоскими днищами, служащий для хранения и перевоза жидкостей, моченых и соленых пищевых продуктов и т.П. (ССРЛЯ т. 1)

Русск. диал.: бо́чка 1. (С.ол./Олон; СР.п./Пск.) 'мера сыпучих тел, содержащая в себе две четверти'; 2. (С.з./Новг.; С.п./Арх.; С.в./Вят.; С.вл.пов./Твер.; СР.п./ Пск.) 'средняя часть рыболовного снаряда, конусообразной формы (мережи, морды и. т. п.) от второго обруча до сужения в конце конуса'; 3. (С.п./Арх.) 'сложенная в виде полуконического свода внутренняя часть русской печи'; 4. (С.в./Перм.) 'головное украшение, род венца, повязки с фольгой, жемчугом и т.п. надеваемое невестой на девичник или под венец'; 5. (Ю.в./Дон) 'широкая прорубь для вынимании рыбы из вентеря, поставленного подо льдом'; 6. (СР.п./Пск.) 'небольшая сеть для лова снетков'; 7. (СР.п./Пск.) 'укрепленный на санях ворот для тяги невода во время зимнего лова рыбы' (СлРНГ 3: );

Русск. ист.: БЪЧЬКА (Новг. І л. 6712 г.) 'сuра' [СРЕВЗНЕВСКИЙ 1:201]; БОЧКА 1. (Оп. им. Ив. Гр., 25. 1583 г.) 'бочка'; 2. (Дон. д. IV 539. 1652 г.) 'мера жидких, сыпучих и твердых тел'; 3. (Колл. Зинченко, № 76. 1665 г.) 'крыша, покрытие здания или его части в виде бочки, сделанной в длину'; 4. (Кн. Тул. и Каш. зав., 10. 1647 г.) 'утолщение вала или ворота в подъемном снаряде; обруч, надеваемый на боевой вододействующий вал кричного молота' [СДРЯ 1: ] $<$ ПС * b ъ с ь k а [ЭССЯ 3: 108] см. еще ФАСМЕР 1: 302; ЧЕРНЫХ 1: 106.

\section{Мар. кадила г. 'кадило' (МРСл)}

Мар.диал. kad'ilä NW, W ${ }_{1}$ 'Weihrauchfass' [MOISIO-SAARINEN 2008: 214];

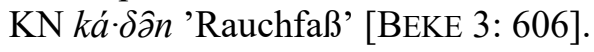

Русские данные:

1.

Русск. лит.: кадило 'металлический сосуд для курения ладаном при богослужения' [ОжЕГОВ]

Русск. диал.: (без названия места) кадило 1. 'церковный сосуд, курильница на цепочках, в которую на жар кладется ладан' 2. 'растение Teucrium (Ajuga) 
chamaepitys, плакун, богородское-зелье, сутловка' [ДАль 2: 72]; кадилка (С.в./Твер.; Б.Ю./Смол.) 'кадило' [СРНГ 12: 298]

Русск. ист.: кадияо 1. (Лавр. Лет. 1091 ) 'благовонное вещество'; 2. (Лавр. Лет. 1072) 'церковный сосуд для курения благовоний'; 3. (Ник. Лект. Х. 42) 'светильник' [СДРЯ 7: 12]; кадико 'церковный сосудъ, въ коемъ на горящіе угли кладется ладонъ для куренія' [СЦСРЯ 2: 151] < прасл. *kadidlo [ЭССЯ 9: 109] < *kadi-dlo (Варбот 1969: 87) < *kaditi [ЭССЯ 9: 107] ${ }^{11}$.

2.

Русск. ист.: кадемие (Чис. VII. 14. XIV в.) 'фимиам' [СДРЯ 7: 11] < старорусск. *kad-en'e ср. прасл. *kadbnъ(jb) [ЭССЯ 9: 115].

\section{Мар. мо́льо 'малявка (рыба)' (МРСл)}

Мар. диал.: л. мол'о, мыл'bl; г. мол'bl 'моль' [САВАТКОВА 1969: 104]; CK Č môle, JT møló, K mol’’ 'allerlei kleine, winzige Fische; ganz kleiner, jüngst ausgeschlüpfter, heuriger Fisch' [BEKE 5: 1434-35]; mø·l'o Mup, mî.l' $\varepsilon$ Mwo, móll' NW, $\mathrm{W}_{1}$ 'Fischbrut (NW W ${ }_{1}$ ); ein Weißfisch (Mup), ein kleiner Fisch (Mwo)' [MoISIO-SAARINEN 2008: 386].

Русские данные:

1.

Русск. лит.: моль 1. 'всякого рода мелкая рыба (обычно - только что выведшаяся); мелкие предметы, мелочь'; 2. 'что-либо, состоящее из отдельных, несоединенных предметов; россыпь (обычно в лесе, сплавляемом не связанными между собой бревнами) ' [ССРЛЯ 6: 1214]; молье собир. 'мелкая рыба, продающаяся не на вес, а ковшами или ведрами' [ССРЛЯ 6: 1216, 571].

Русск. диал.: молье 1. (С.в./Волог.) ${ }^{12}$ 'самая мелкая свежая рыба разных сортов, которая продавалась не на вес а ковшами или ведрами'; 2. (С.ол./Олон.) 'сушенная мелкая рыба, а также молодь'; 2. (С.в./Перм.) мн. ч. 'окуни, плотва, щуки' [СРНГ 18].

Русск. ист.: мбхь (Кн. Расх. Кир. М. № 2, 16, 1567 г.) 'мелкая рыба' (СДРЯ 9: 257) < прасл. *molb [ЭССЯ 19: 205-206]; мөлекъ (Кн. Прих.-расх. Свир. М. № 21, 59, 1657 г.) 'мелкая рыба' [СДРЯ 9: 243] < прасл. *molbkъ [ЭССЯ 19: 206-207].

2.

Русск. лит.: -; Русск. диал.: мул (Ю.ю./Курск.) 'топкий ил, остающийся после весеннего половодья [СРНГ 18: 340]; муль 1. (С.в./Перм.) 'мулек'; 2. (С.з./Новг.) 'мелкий окунь'; мулье собир. (С.в./Перм.) 'мелкая рыбка, мальки' [СРНГ 18: 348]; мулек (С.з./Новг.) 'мелкий окунь, рыба Phoxinus phoxinus гольян' (там же).

11 В данном случае вряд ли можно говорить об общеславянском происхождении слова, так как специальное значение глагола 'курить благовонное вещество' появилось в старославянском языке, и только оттуда распространялось оно в восточно- и западно-славянские языки. Глагол *kaditi можно рассмотреть как праславянский диалектизм.

12 Систему сокращений диалектной паспортировки см. АдягАши 2005: 63-65. 
Русск. ист.: муль (Назиратель XVI в.) 'тина' [СДРЯ 9: 307] < прасл. *mulъ, *mulb [ЭССЯ 20: 185] ${ }^{13}$.

Чувашские данные:

Чув. диал.: (Пшкрт) mol' 'название рыбы' [Ашм. 8: 264]

Татарские данные:

Тат. диал.: М(байк.) тёlе̌ 'мелкая рыба' [ТТДС 1993: 221]; М(хвл.) mölök 'малек' [ТТДС 1969: 316]; М(кар.) mul' 'малек' [ТТДС 1969: 309].

\section{Литература}

АДяГАши 2002а: Адягаши, К., К вопросу о появлении сверхкратких лабиальных гласных в марийском языке // Языковые контакты Поволжья (ред. Йома Луутонен). Симпозиум в городе Турку 16-18.8. 2001 г. Publications of the Department of Finnish and General Linguistics of the University Turku. 70-86.

АДяГАши 2002б: Адягаши, К., Название черемис в средневековых источниках // Пермистика 9: Вопросы пермской и финно-угорской филологии. (Отв. ред. И.В. Тараканов) Ижевск. 102-108.

АдяГАши 2005: Адягаши, К. Ранние русские заимствования тюркских языков ВолгоКамского ареала. Часть I. Этимологический справочник. Studies in Linguistics of the Volga-region Vol. II. Debrecen University Press, Debrecen.

Ашм.: Н.И. Ашмарин, Словарь чувашского языка 1-17. Казань-Чебоксары.

ВАРБОТ 1969: Варбот Ж.Ж., Древнерусское именное словообразование. Наука. Москва.

Грузов 1964: Грузов, Л.П., Фонетика диалектов марийского языка в историческом освещении. Йошкар-Ола.

ДАль 1882/1982: Даль, В., Толковый словарь живого великорусского языка т. 1-4. Москва, Русский язык.

ДАМАСКИН 1785: Словарь языков разных народов в Нижегородской епархии обитающихъ, имянно Россиянъ, Татаръ, Чювашей, Мордвы и Черемисъ. По высочайшему соизволению и повелению Ея императорского Величества премудрей Государыни Екатерины Алексеевны, императрицы и самодержицы Всероссийской, по алфавиту Российскихъ слов расположенной и в Нижегородской семинарии отъ знающихъ оныя языки священников и семинаристов подъ присмотром преосвященного Дамаскина, эпископа Нижегородского и Алатырского, сочиненной в 1785 г.

ЕФимОв 2000: Ефимов, Л.А., Системы просвещенияя нерусских народов и чувашские школы Поволжья и Приуралья последней трети XIX - начала XX веков. Чебоксары.

МРСл: Марийско-русский словарь. Отв. ред. Б.А. Серебренников. Государственное издательство иностранных и национальных словарей. Москва, 1956.

13 Праславянское происхождение существительного муль 'тина' ставится под вопрос, так как это слово первый раз зафиксировано в XVI в. в переводном произведении на русском языке (cм. RÁDULY 2000), и, потому что географические расстояния между южнорусским и севернорусскими данными слишком велики для того, чтобы связать основное значение южнорусского слова метафорическим значением на севере. Южнорусское диалектное слово видимо является результатом украинско-южнорусских языковых контактов, а северные диалектные варианты с мягкой основой имеют другое происхождение. 
ОЖЕГОВ 2008: Ожегов С. И., Словарь русского языка. Под общей редакцией Л. И. Скворцова. 24-ое издание, испр. ОНИКС, Москва.

САВАТкОВА 1969: Саваткова А.А., Русские заимствования в марийском языке. Марийское книжное издательство. Йошкар-Ола.

СДРЯ: Словарь русского языка XI-XVII вв. т. 1-. Наука, Москва.

СЕЛИЩЕВ 1927: Селищев, А.М., Русские говоры Казанского края и русский язык у чуваш и черемис. //Ученые записки института языка и литературы Т. 1. Москва. 60-70.

СЕРГЕЕВ 2003: Сергеев, О.А., Из истории отечественной лексикографии. Словарь черемисского языка с российским переводом. Марийский государственный университет, Йошкар-Ола.

СкРынникОВ 1997: Скрынников, Р.Г. История российская IX-XVII вв. Москва.

СмоляковА 1977: Смолякова, Л.П. Формирование фонетической системы русских говоров Волго-Камья (с учетом иноязычных влияний). Москва, Наука.

СРНГ: Словарь русских народных говоров (Ред. Ф. П. Филин, Ф. П. Сороколетов) 1-. Наука, Ленинград.

ССРЛЯ: Словарь современного русского литературного языка 1-17. Наука. МоскваЛенинград.

СЦСРЯ: Словарь церковно-славянскаго и русскаго языка, составленный Вторымъ отдşлениемъ Императорской Академии наукъ. Томъ II. Санктпетербург, 1847.

ТТДС 1969: Татар теленең диалектологик сүзлеге. Ред. Л.Т. Махмутова. Татарстан китап нәшряте. Казан.

ТТДС 1993: Татар теленең диалектологик сүзлеге. Ред. Д.Б. Рамазанова. Татарстан китап нәшряте. Казан.

ФАСМЕР 1987: Фасмер, М. Этимологический словарь русского языка I-IV. Перевод с немецкого и дополнения О. Н. Трубачева. Издание второе, стереотипное. Прогресс. Москва.

ЧЕРНЫХ 1999: Черных, П. Я., Историко-этимологический словарь современного русского языка в 2 томах. Русский язык, Москва.

ЭССЯ: Этимологический словарь славянских языков. Праславянский лексический фонд. 1- . Под ред. О.Н. Трубачева. Москва, 1974-.

AGYAGÁsi 2013: Agyagási, K. О трех редких диалектизмах, легших в основу некоторых русских заимствований в марийском языке // Slavica 42: 165-176.

AGYAGÁSI 2014: Agyagási K., Опосредование лексических единиц как характерный действующий механизм доминантного булгарского языка Волго-Камского языкового ареала // Slavica 43: 9-18.

AgYAGÁsı 2019: Agyagási, K. Chuvash historical phonetics. With an Appendix on the role of Proto-Mari in the history of Chuvash vocalism. Harrassowitz, Turcologica Band 117, Wiesbaden. В печати.

BEKE 1997-2002: Beke, Ö. Mari nyelvjárási szótár (Tscheremissisches Dialektwörterbuch) 1-9. Hrsg. von János Pusztay. Savariae, 1997-2001.

BERECZKI 1968: Bereczki, G. Wichtigere lautgeschichtliche Lehren der russischen Lehnwörter im Tscheremissischen // Congressus secundus Internationalis Fenno-Ugristarum Helsingiae habitus 23-28. VIII. 1965. Pars I. Acta Linguistica. Helsinki, Societas FennoUgrica. 70-76.

BERECZKI 1992. Bereczki, G., Grundzüge der tscheremissischen Sprachgeschichte II. Studia Uralo-Altaica 34. Szeged.

BERECZKI 1994: Bereczki, G., Grundzüge der tscheremissischen Sprachgeschichte I. Studia Uralo-Altaica 35. Szeged. 
MOISIO-SAARINEN 2008: Moisio A. und Saarinen S., Tscheremissisches Dialektwörterbuch. Suomalais-Ugrilainen Seura, Kotimaisten kielten tutkimuskeskus. Helsinki.

PAASONEN 1974: Paasonen, H. Csuvas szójegyzék. Budapest, 1908. репринт 1974: Tschuwaschishes Wörterverzeichnis. Eingeleitet von A. Róna-Tas. Studia Uralo-Altaica 4. Szeged.

RÁDULY 2000: Ráduly, Zsuzsanna, Глоссирующая синонимия в «Назиретеле» // Studia Russica 18: 227-230.

SEBEOK-RAUN 1956: Sebeok, T., Raun, A., The First Cheremis Grammar (1775). The ewberry Library, Chicago.

SEREBRENNIKOV 1957: Serebrennikov, B. Zur Geschichte der a-Laut im tscheremissischen und Tschuwaschen // UAJb 29: 224-230.

Klára AGYAGÁSI

University of Debrecen

Debrecen, Hungary

agyagasi.klara@arts.unideb.hu 